\title{
PAPER
}

\section{Effect of chronic pallidal deep brain stimulation on off period dystonia and sensory symptoms in advanced Parkinson's disease}

\author{
T J Loher, J-M Burgunder, S Weber, R Sommerhalder, J K Krauss
}

J Neurol Neurosurg Psychiatry 2002;73:395-399

See end of article for authors' affiliations

.....................

Correspondence to: Prof Dr J K Krauss, Department of Neurosurgery, University Hospital, Klinikum Mannheim, Theodor-Kutzer-Ufer 1-3, 68167 Mannheim

Germany; joachim.krauss@ nch.ma.uni-heidelberg.de

Received for publication 21 January 2002 In revised form 10 April 2002

Accepted 6 June 2002

\begin{abstract}
Objective: To investigate the efficacy of chronic pallidal deep brain stimulation (DBS) on off period dystonia, cramps, and sensory symptoms in advanced Parkinson's disease (PD).

Methods: 16 patients ( 6 women, 10 men; mean age at surgery 65 years) suffering from advanced PD were followed up prospectively for one year after implantation of a monopolar electrode in the posteroventral lateral globus pallidus internus. Unilateral DBS was performed in 9 patients. 10 patients had bilateral procedures (contemporaneous bilateral surgery in 7 and staged bilateral surgery in 3 instances). The decision whether to perform unilateral or bilateral surgery depended on the clinical presentation of the patient. Patients were formally assessed preoperatively, at 3-5 days, 3 months, and 12 months after surgery.

Results: In patients who underwent unilateral surgery, pain was present in 7 (78\%), off dystonia in 5 $(56 \%)$, cramps in $6(67 \%)$, and dysaesthesia in $4(44 \%)$. In patients who underwent bilateral surgery, pain was present in $7(70 \%)$, off dystonia in $6(60 \%)$, cramps in $7(70 \%)$, and dysaesthesia in $4(40 \%)$. With unilateral DBS, contralateral off period dystonia was improved by $100 \%$ at 1 year postoperatively, pain by $74 \%$, cramps by $88 \%$, and dysaesthesia by $100 \%$. There was less pronounced amelioration of ipsilateral off period dystonia and sensory symptoms. With bilateral DBS, total scores for dystonia were improved by $86 \%$, for pain by $90 \%$, for cramps by $90 \%$, and for dysaesthesia by $88 \%$. The benefit appeared early at the first evaluation 3-5 days after surgery and was stable throughout the follow up period.

Conclusions: Pallidal DBS yields major improvement of off period dystonia, cramps, and sensory symptoms in patients with advanced PD.
\end{abstract}

$\mathrm{F}$ unctional stereotactic surgery is now well established for the treatment of the motor symptoms of advanced Parkinson's disease (PD). Chronic deep brain stimulation (DBS) nowadays is considered an accepted alternative to radiofrequency lesioning. ${ }^{1-4}$ Furthermore, chronic DBS has widened the spectrum of surgery for movement disorders, in particular with regard to bilateral procedures. ${ }^{56}$ The globus pallidus internus (GPi) and the subthalamic nucleus (STN) are the targets of choice for treatment of advanced PD in contemporary functional neurosurgery. ${ }^{7-10}$ It has been shown that chronic DBS of these targets yields a benefit both in motor function and in functional disability.

The effect of surgical treatment in patients with PD is assessed most commonly by the unified Parkinson's disease rating scale (UPDRS). ${ }^{11}$ While the UPDRS allows appropriate evaluation of motor symptoms and functional disability, it is not suitable to determine changes in off period dystonia, cramps, and sensory symptoms, which are common features and a source of great discomfort in advanced PD. Shulman and colleagues recently reported a prevalence of sensory symptoms of $63 \%$ in patients with PD. ${ }^{12}$ Thus far, however, data are scarce on the efficacy of stereotactic surgery with regard to off period dystonia, cramps, and sensory symptoms. No systematic study of the benefit of unilateral versus bilateral DBS has been published thus far.

Recently, we published the results of our one year follow up study on chronic pallidal DBS in 16 consecutive patients with advanced PD, showing major improvement in motor symptoms and functional disability. ${ }^{13}$ Here, we focus on the prospective assessment of the effect of pallidal DBS on off period dystonia, cramps, and sensory symptoms in advanced PD.

\section{PATIENTS AND METHODS \\ Patients}

Advanced idiopathic PD was diagnosed in all patients according to clinical criteria. All were responsive to levodopa but their parkinsonian symptoms were not sufficiently controlled. Furthermore, patients suffered from additional disability due to levodopa induced side effects, such as dyskinesias and on-off motor fluctuations. Exclusion criteria were major cognitive dysfunction, major depression or other psychiatric disorders, features suggestive of atypical parkinsonian syndromes, or abnormal brain scans such as major cerebral atrophy. Sixteen patients, 6 women and 10 men, were enrolled in the present study. Mean age at surgery was 64.9 years (range 49-77 years). Mean age at onset of parkinsonian symptoms was 46.9 years (range 32-59 years), and duration of symptoms before surgery was 18.2 years (range 6-30 years). Table 1 shows the baseline characteristics of the patients stratified according to whether they underwent unilateral or bilateral surgery.

\section{Neurosurgical procedure}

Unilateral procedures were performed in nine patients with a major lateralisation of symptoms. Three of them had secondary staged bilateral surgery later on. Seven patients who had higher scores for axial symptoms underwent primarily

Abbreviations: $\mathrm{CT}$, computed tomography; DBS, deep brain stimulation; GPi, globus pallidus internus; PD, Parkinson's disease; STN, subthalamic nucleus; UPDRS, unified Parkinson's disease rating scale 
Table 1 Baseline characteristics before surgery

\begin{tabular}{|c|c|c|}
\hline Characteristic & $\begin{array}{l}\text { Unilateral } \\
\text { stimulation }\end{array}$ & $\begin{array}{l}\text { Bilateral } \\
\text { stimulation }\end{array}$ \\
\hline \multicolumn{3}{|l|}{ Sex } \\
\hline Male & 6 & 5 \\
\hline Female & 3 & 5 \\
\hline \multicolumn{3}{|l|}{ Age at operation (years) } \\
\hline Mean (SD) & $65.1(5.4)$ & $64.6(9.9)$ \\
\hline Range & $57-71$ & $49-77$ \\
\hline \multicolumn{3}{|l|}{ Age at onset of disease (years) } \\
\hline Mean (SD) & $48.9(7.4)$ & $45.1(8.1)$ \\
\hline Range & $34-57$ & $32-59$ \\
\hline \multicolumn{3}{|l|}{ Duration of disease (years) } \\
\hline Mean (SD) & $16.7(6.3)$ & $19.6(7.9)$ \\
\hline Range & $10-27$ & $6-30$ \\
\hline \multicolumn{3}{|l|}{ Schwab and England activities of daily living score (\%) } \\
\hline \multicolumn{3}{|l|}{ Off period } \\
\hline Mean (SD) & $31.1(15.4)$ & $28.0(15.5)$ \\
\hline Range & $20-60$ & $10-60$ \\
\hline \multicolumn{3}{|l|}{ On period } \\
\hline Mean (SD) & $56.7(16.6)$ & $51.0(24.2)$ \\
\hline Range & $40-80$ & $20-80$ \\
\hline \multicolumn{3}{|l|}{ Hoehn and Yahr stage } \\
\hline \multicolumn{3}{|l|}{ Off period } \\
\hline Median & $4.2(0.8)$ & $4.4(0.7)$ \\
\hline Range & $3-5$ & $3-5$ \\
\hline \multicolumn{3}{|l|}{ On period } \\
\hline Median & $3.5(0.5)$ & $3.9(0.9)$ \\
\hline Range & $3-4$ & $3-5$ \\
\hline \multirow{2}{*}{\multicolumn{3}{|c|}{$\begin{array}{l}\text { Motor unified Parkinson's disease rating scale } \\
\text { Off period }\end{array}$}} \\
\hline & & \\
\hline Mean & 57.2 (13.7) & $63.4(17.4)$ \\
\hline Range & $31-69$ & $36-88$ \\
\hline \multicolumn{3}{|l|}{ On period } \\
\hline Mean & $29.1(6.5)$ & $37.6(17.3)$ \\
\hline Range & $19-39$ & $15-59$ \\
\hline \multicolumn{3}{|l|}{ Medication } \\
\hline Levodopa/peripheral decarboxylase inhibitor (mean) & 881.3 & 970.5 \\
\hline Total levodopa equivalent dose (mean) & 1126.7 & 1235.5 \\
\hline \multicolumn{3}{|c|}{$\begin{array}{l}\text { The total levodopa equivalent dose was calculated as the sum of the dose of regular levodopa-carbidopa (or } \\
\text { levodopa-benserazide), plus } 0.75 \text { times the dose of controlled release levodopa-carbidopa, plus } 10 \text { times the } \\
\text { dose of bromocriptine, plus } 100 \text { times the dose of pergolide, plus } 100 \text { times the dose of pramipexole. For } \\
\text { patients who were receiving tolcapone, the sum of the dose of regular levodopa and } 0.75 \text { times the dose of } \\
\text { controlled release levodopa was multiplied by a factor of } 1.33 \text {. }\end{array}$} \\
\hline
\end{tabular}

contemporaneous bilateral surgery. Monopolar DBS electrodes (3388, Medtronic Inc, Minneapolis, Minnesota, USA) were implanted into the posteroventral lateral GPi under computed tomographic (CT) stereotactic conditions, as reported in detail elsewhere. ${ }^{13-18}$ Microelectrode recording and macrostimulation techniques were used to further refine the target. The implantable pulse generators (Itrel II, Medtronic Inc) were placed in a subcutaneous pouch below the clavicle. Postoperatively, CT scans were done of all patients. The implantable pulse generator was first programmed within 24 hours after operation, in general, and stimulation settings were adjusted on follow up visits.

\section{Clinical assessment and analysis of data}

All patients underwent standardised assessments including UPDRS both off levodopa (practically defined off, 12 hours after overnight withdrawal of antiparkinsonian medication) and on levodopa (best on, after administration of levodopa), Hoehn and Yahr staging, Schwab and England activities of daily living scale, modified Obeso dyskinesia rating scale, mini-mental state examination, Hamilton depression scale, and a standardised video protocol. Additional information on dosage of levodopa and other antiparkinsonian drugs, patient diary for fluctuations, dyskinesia severity and location, and global clinical impression were obtained at each patient's visit. All formal evaluations were performed by the neurological team members.

In addition, the following off symptoms were evaluated: pain, dystonia, cramps, and dysaesthesia. The severity was described by the patients according to an ordinal scale ranging from 0 to $4 \quad(0=$ absent, $\quad \mathrm{l}=$ slight, $2=$ moderate, $3=$ pronounced, $4=$ severe). The rating for each off symptom was applied to six different parts of the body (neck, trunk, upper and lower extremities at each side) resulting in a maximal total score of 24 points. Follow up assessments were performed between 3-5 days postoperatively, at 3 months, and at 1 year after surgery.

Outcome measures at baseline and at defined follow up visits were described in mean scores separately for patients treated with unilateral and bilateral DBS. To investigate the hypothesis of a postoperative change we compared the follow up scores with the preoperative score using Wilcoxon's paired rank test (one tailed with regard to a supposed improvement). A $p$ value of $<0.05$ was considered to indicate significance.

\section{RESULTS}

Occurrence and severity of off period dystonia, cramps, and sensory symptoms

Table 2 shows the mean (SD) preoperative total scores of off period dystonia, cramps and sensory symptoms. After unilateral surgery, pain was present in seven of nine patients (78\%), off dystonia in five (56\%), cramps in six $(67 \%)$, and dysaesthesia in four $(44 \%)$. After bilateral surgery, pain was present in seven of 10 patients $(70 \%)$, off dystonia in six $(60 \%)$, cramps in seven (70\%), and dysaesthesia in four $(40 \%)$. Off period dystonia most frequently affected the toes or feet, while cramps usually affected the thighs. Typically, cramps could be relieved by massaging the thighs. 


\begin{tabular}{lll}
$\begin{array}{l}\text { Table } 2 \\
\text { dystonia, cramps, and sensory symptoms }\end{array}$ & \multicolumn{2}{c}{ Occurrence and severity of off period } \\
\hline Off symptom & $\begin{array}{l}\text { Unilateral } \\
\text { stimulation }\end{array}$ & $\begin{array}{l}\text { Bilateral } \\
\text { stimulation }\end{array}$ \\
\hline $\begin{array}{l}\text { Pain } \\
\text { Number of patients }\end{array}$ & 7 & 7 \\
$\begin{array}{l}\text { Mean (SD) total score } \\
\text { Dystonia } \\
\text { Number of patients } \\
\text { Mean (SD) total score }\end{array}$ & $9.0(5.3)$ & $8.0(5.9)$ \\
$\begin{array}{c}\text { Cramps } \\
\text { Number of patients } \\
\text { Mean (SD) total score }\end{array}$ & 5 & 6 \\
$\begin{array}{c}\text { Dysaesthesia } \\
\text { Number of patients } \\
\text { Mean (SD) total score }\end{array}$ & $3.4(2.3)$ & $3.5(2.6)$ \\
\hline
\end{tabular}

\section{Operative morbidity and follow up}

There were no intraoperative complications. Postoperatively, one patient had a haemorrhage at the site of the pacemaker, which required revision. Another patient had a small asymptomatic pallidal haematoma, which was detected on routine postoperative CT and had a prolonged micropallidotomy effect. All patients were available for follow up. One patient who had bilateral surgery died seven months after surgery secondary to urosepsis. The one year follow up was obtained 18 months after surgery in one patient. In the three patients who underwent contralateral surgery later on, the last available follow up at nine months was used. Thus, the mean follow up was 11.7 months. All patients had continuous stimulation. The mean values of settings at the one year follow up were as follows: amplitude $1.4 \mathrm{~V}$ (range 0.8-2.0), frequency 146 pulses/s (range 125-160), and pulse width $210 \mu \mathrm{s}$ in patients with unilateral stimulation; and amplitude $1.0 \mathrm{~V}$ (range 0.6-1.8), frequency 138 pulses/s (range 130-145), and pulse width $210 \mu \mathrm{s}$ in patients with bilateral stimulation.

\section{Clinical outcome}

Detailed data regarding the cardinal symptoms of PD according to off period and on period UPDRS assessments have been published previously. ${ }^{13}$ In summary, in patients with unilateral GPi DBS the UPDRS activities of daily living score off levodopa improved by $34 \%$ at three months and by $33 \%$ at 12 months, while the motor off score decreased by $38 \%$ at three months and by $38 \%$ at 12 months. Bilateral DBS ameliorated the activities of daily living off score by $36 \%$ at three months and by $34 \%$ at 12 months, while there was a $36 \%$ improvement of the motor off score at three months and a $41 \%$ improvement at 12 months. There was also significant improvement of on

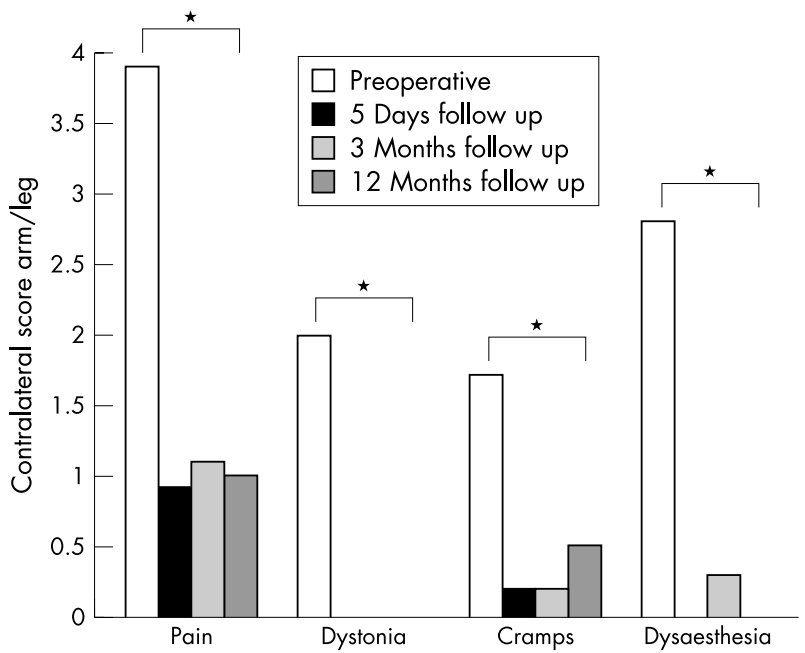

Figure 1 Effect of unilateral deep brain stimulation of the globus pallidus internus on off period dystonia, cramps, and sensory symptoms. Mean baseline scores and follow up scores (percentage improvement compared with preoperative scores) during continuous pallidal stimulation are shown. Bar graphs display the unilateral scores of the arm and leg contralateral to the stimulation site.

symptoms and of on-off fluctuations. There were no significant changes in levodopa medication or levodopa equivalents.

\section{Postoperative assessment of off period dystonia, cramps, and sensory symptoms}

Dystonia, cramps, and sensory symptoms did not develop in the follow up period, if not already present at the preoperative assessment. In patients undergoing unilateral GPi DBS there was a significant and sustained improvement of contralateral off period dystonia $(-100 \%, \mathrm{p}=0.019)$, pain $(-74.4 \%$, $\mathrm{p}=0.009)$, cramps $(-88.2 \%, \mathrm{p}=0.020)$, and dysaesthesia $(-100 \%, p=0.033)$ throughout the follow up period up to one year (table 3). The benefit appeared early at the first postoperative evaluation within days after surgery (fig 1). There were no significant differences between the ratings of the 3 month and the 12 month evaluation (table 3). Ipsilateral off period dystonia, pain, cramps, and dysaesthesia had also improved at the one year follow up; however, the improvements were less pronounced and not significant. No useful statistical analysis of the effect of unilateral GPi DBS on ipsilateral off period dystonia and sensory symptoms could be done in the three patients who underwent staged bilateral surgery. Two of the three patients who first had unilateral stimulation and underwent contralateral stimulation later on had only marginal scores for ipsilateral off period dystonia and

Table 3 Off period dystonia, cramps, and sensory symptoms before, 3-5 days after, 3 months after, and 12 months after unilateral deep brain stimulation of the globus pallidus internus

\begin{tabular}{|c|c|c|c|c|c|c|c|c|c|c|c|}
\hline \multirow[b]{2}{*}{ Off period symptom } & \multirow[b]{2}{*}{$\begin{array}{l}\text { Score } \\
\text { range }\end{array}$} & \multirow[b]{2}{*}{ Baseline } & \multicolumn{9}{|l|}{ Follow up } \\
\hline & & & 5 Days & $\begin{array}{l}\text { Change } \\
0-5 \text { days } \\
(\%)\end{array}$ & p Value & 3 Months & $\begin{array}{l}\text { Change 0-3 } \\
\text { months (\%) }\end{array}$ & $\mathrm{p}$ Value & 12 Months & $\begin{array}{l}\text { Change } \\
0-12 \text { months } \\
(\%)\end{array}$ & p Value \\
\hline Dystonia total score & $0-24$ & $3.4(2.3)$ & $0.2(0.4)$ & -94.1 & 0.021 & $0.4(0.9)$ & -88.2 & 0.021 & $0.4(0.9)$ & -88.2 & 0.021 \\
\hline Dystonia contralateral score & $0-8$ & $2.0(0.7)$ & $0.0(0.0)$ & -100 & 0.019 & $0.0(0.0)$ & -100 & 0.019 & $0.0(0.0)$ & -100 & 0.019 \\
\hline Pain total score & $0-24$ & $9.0(5.3)$ & $2.4(5.2)$ & -73.3 & 0.009 & $2.9(4.3)$ & -67.8 & 0.009 & $2.6(2.8)$ & -71.1 & 0.009 \\
\hline Pain contralateral score & $0-8$ & $3.9(2.0)$ & $0.9(2.3)$ & -76.9 & 0.014 & $1.1(2.3)$ & -71.8 & 0.014 & $1.0(1.5)$ & -74.4 & 0.009 \\
\hline Cramps total score & $0-24$ & $3.5(3.4)$ & $0.5(0.8)$ & -85.7 & 0.013 & $0.2(0.4)$ & -94.3 & 0.013 & $0.7(0.8)$ & -80.0 & 0.021 \\
\hline Cramps contralateral score & $0-8$ & $1.7(1.4)$ & $0.2(0.4)$ & -88.2 & 0.020 & $0.2(0.4)$ & -88.2 & 0.020 & $0.5(0.8)$ & -88.2 & 0.020 \\
\hline Dysaesthesia total score & $0-24$ & 4.5 (3.5) & $0.0(0.0)$ & -100 & 0.034 & $0.3(0.5)$ & -93.3 & 0.033 & $0.0(0.0)$ & -100 & 0.034 \\
\hline $\begin{array}{l}\text { Dysaesthesia contralateral } \\
\text { score }\end{array}$ & $0-8$ & $2.8(2.1)$ & $0.0(0.0)$ & -100 & 0.033 & $0.3(0.5)$ & -89.3 & 0.055 & $0.0(0.0)$ & -100 & 0.033 \\
\hline
\end{tabular}




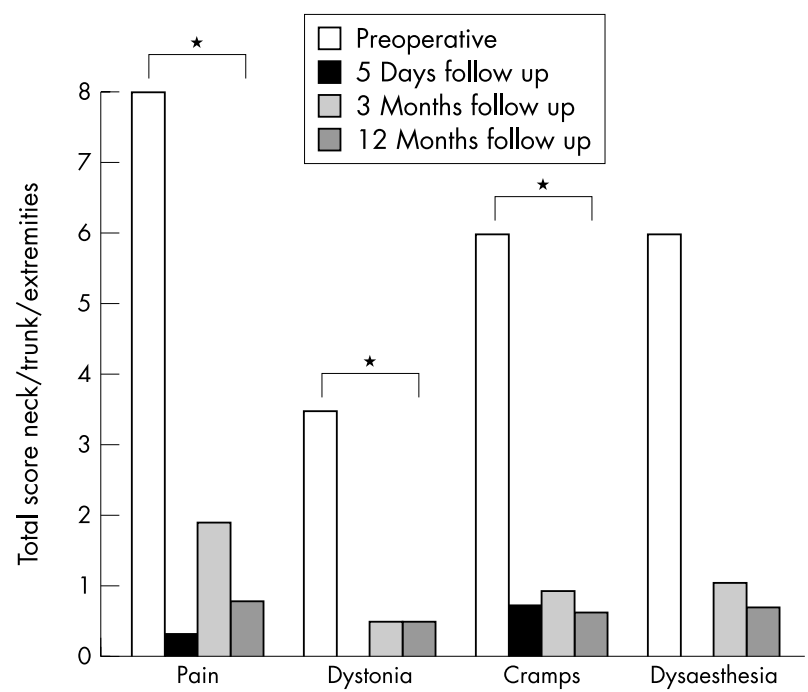

Figure 2 Effect of bilateral deep brain stimulation of the globus pallidus internus on off period dystonia, cramps, and sensory symptoms. Mean baseline scores and follow up scores (percentage improvement compared with preoperative scores) during continuous pallidal stimulation are shown. Bar graphs display the totals scores of neck, trunk, and both upper and lower extremities.

sensory symptoms. The total scores in patients with unilateral stimulation, including the ratings for the neck and trunk, also reflected major improvement of off dystonia $(-88.2 \%$, $\mathrm{p}=0.021)$, pain $(-71.1 \%, \mathrm{p}=0.009)$, cramps $(-80.0 \%$, $\mathrm{p}=0.021)$, and dysaesthesia $(-100 \%, \mathrm{p}=0.034)$.

In patients with bilateral stimulation the total score for dystonia improved by $85.7 \%(\mathrm{p}=0.021)$, for pain by $90.0 \%$ $(\mathrm{p}=0.014)$, for cramps by $90.0 \%(\mathrm{p}=0.021)$, and for dysaesthesia by $88.3 \%(p=0.090)$ at the one year follow up (fig 2 ). Again, the improvements were sustained throughout the follow up period. As with unilateral stimulation, there was no significant change between the 3 month and the 12 month follow up assessments.

\section{DISCUSSION}

Our study clearly shows that chronic pallidal stimulation ameliorates off period dystonia, cramps, and sensory symptoms in advanced PD. In patients undergoing unilateral surgery there was a distinct and significant contralateral stimulation effect, whereas the improvement of ipsilateral symptoms was less striking. In the bilateral stimulation group there was also major improvement of all corresponding total scores for pain, dystonia, cramps, and dysaesthesia. The benefit appeared early and remained stable throughout the follow up at one year.

The frequency of off period dystonia and sensory symptoms in our patients is similar to that seen in other series of patients with advanced PD. ${ }^{19-24}$ Pain was the most frequently reported symptom, present in more than $70 \%$ of patients. Quinn and colleagues have shown a strong association between off period dystonia and pain, which is in accordance with the findings in our study. ${ }^{20}$ Off period dystonia and pain can be rather vexing and disabling features of advanced PD. Pain and dystonia off medication are found more frequently in patients with young onset PD. ${ }^{25}$ Cramps appear to occur more often off levodopa in advanced PD.

Only a few studies have addressed the impact of functional stereotactic surgery on off period dystonia and pain in patients with advanced PD. In a prospective one year follow up study of 21 patients with $\mathrm{PD}$ undergoing unilateral pallidotomy, Honey and colleagues found a sustained significant reduction of pain of about $40 \%{ }^{26}$ This result is consistent with findings of the effectiveness of pallidotomy in two other studies that reported major reduction of "pain and discomfort scores" in 9 of 12 patients ${ }^{27}$ and a very good effect with abolition of dystonia and pain in 12 of 24 patients. ${ }^{28}$ Only one study reported on the effectiveness of GPi DBS for off period dystonia with complete relief in four patients and a major reduction in one of nine patients. ${ }^{29}$ In two other studies, the Grenoble group described striking effects of bilateral STN DBS on off period dystonia and pain. In their 12 month follow up study of 16 patients with painful off period dystonia, they reported complete relief of dystonia and pain in 12 patients and a decrease in the other 4 patients. ${ }^{30}$ In another study of eight patients with severe off period dystonia major improvement of dystonia (-90\%) and pain $(-66 \%)$ was found at the six month follow up assessment. $^{31}$

According to the current model of basal ganglia pathophysiology in PD, it is thought that the cardinal symptoms of PD are secondary to increased neuronal activity of the STN and GPi subsequent to striatal dopamine depletion. ${ }^{32-34}$ The mechanisms underlying off period dystonia are not completely understood but it has been proposed that it may also be related to neuronal hyperactivity. Ablative surgery and DBS of the STN or of the GPi therefore has a rational basis and has been shown to be effective for both targets in clinical practice. The improvement in off motor function appears to be higher in STN DBS than in GPi DBS. While STN DBS and GPi DBS have different profiles regarding the alleviation of on period dyskinesias early after surgery, the alleviation of off period dystonia appears to be comparable. The similar effect on off period dystonia may be related to common functional mechanisms. ${ }^{31} 3536$

Apart from dystonia and pain, the presence of off period dysaesthesia in advanced PD is puzzling. The sensory function of the basal ganglia is not well known..$^{37-39}$ It is thought that the basal ganglia control automatic or highly trained movements in relation to sensory input. The basal ganglia circuitry has also been postulated to "gate" sensory processing. Several studies found somatosensory deficits and abnormalities of sensorimotor integration and proprioception in patients with PD. ${ }^{1240-46}$ Studies of somatosensory evoked potentials in PD patients have given conflicting results. While some groups showed decreased parietal N20 and frontal N30 somatosensory evoked potentials components in patients with $\mathrm{PD}^{47-49}$ others failed to replicate these findings. ${ }^{50-52}$ In a recent positron emission tomography study, a distinct reduction of sensory evoked brain activation was found in contralateral cortical (parietal and frontal) and subcortical (globus pallidus and putamen) structures in patients with $\mathrm{PD} .^{53}$

In conclusion, the present study shows that patients with PD with off period dystonia, cramps, and sensory symptoms benefit greatly from pallidal DBS. Disabling off period dystonia in advanced PD alone may be considered to be a good indication for functional stereotactic surgery. Further comparative studies are needed to decide which target is best suited in the individual patient. Long term results are still limited and it will be important to investigate the chronic effects of prolonged stimulation.

\section{ACKNOWLEDGEMENTS}

We thank Pietro Ballinari for his help with the statistical analysis of the data.

\section{Authors' affiliations}

TJ Loher, JM Burgunder, S Weber, R Sommerhalder, Department of Neurology, Inselspital, University of Berne, Berne, Switzerland

J K Krauss, Department of Neurosurgery, University Hospital, Klinikum Mannheim, Mannheim, Germany

Competing interests: J K Krauss is a consultant to Medtronic, Inc

\section{REFERENCES}

1 Hallet M, Litvan I. Scientific position paper of the Movement Disorder Society. Evaluation of surgery for Parkinson's disease. Task Force on 
Surgery for Parkinson's Disease of the American Academy of Neurology Therapeutic and Technology Assessment Committee. Mov Disord 2000;15:436-8

2 Benabid AL, Koudsie A, Benazzouz A, et al. Deep brain stimulation for Parkinson's disease. Adv Neurol 2001;86:405-12.

3 Lang AE. Surgery for Parkinson's disease. A critical evaluation of the state of the art. Arch Neurol 2000;57:1 $118-25$

4 Gross RE, Lozano AM. Advances in neurostimulation for movement disorders. Neurol Res 2000;22:247-58.

5 Kumar R, Lang AE, Rodriguez-Oroz MC, et al. Deep brain stimulation of the globus pallidus pars interna in advanced Parkinson's disease. Neurology 2000;55(suppl 6):S34-9.

6 Kumar R, Lozano AM, Sime E, et al. Comparative effects of unilateral and bilateral subthalamic nucleus deep brain stimulation. Neurology 1999:53:561-6.

7 Burchiel KJ, Anderson VC, Favre J, et al. Comparison of pallidal and subthalamic nucleus deep brain stimulation for advanced Parkinson's disease: results of a randomized, blinded pilot study. Neurosurgery 1999:45:1375-82.

8 Volkmann J, Allert N, Voges J, et al. Safety and efficacy of pallidal or subthalamic nucleus stimulation in advanced PD. Neurology $2001 ; 56: 548-51$.

9 Krack P, Pollak P, Limousin P, et al. Subthalamic nucleus or internal pallidal stimulation in young onset Parkinson's disease. Brain 1998:121:451-7.

10 The Deep-Brain Stimulation for Parkinson's Disease Study Group. Deep-brain stimulation of the subthalamic nucleus or the pars interna of the globus pallidus in Parkinson's disease. N Engl J Med 2001;345:956-63.

11 Fahn S, Elton RL, members of the UPDRS Development Committee. Unified Parkinson's disease rating scale. In: Fahn S, Marsden CD, Goldstein M, et al, eds. Recent development in Parkinson's disease, vol 2. Florham Park: Macmillan, 1987:153-63

12 Shulman LM, Taback RL, Bean J, et al. Comorbidity of the nonmotor symptoms of Parkinson's disease. Mov Disord 2001; 16:507-10.

13 Loher TJ, Burgunder JM, Pohle T, et al. Long-term pallidal deep brain stimulation in patients with advanced Parkinson disease: 1-year follow-up study. J Neurosurg 2002;96:844-53.

14 Krauss JK, Desaloms M, Lai EC, et al. Microelectrode-guided posteroventral pallidotomy for treatment of Parkinson's disease: postoperative magnetic resonance imaging analysis. J Neurosurg 1997;87:358-67.

15 Krauss JK, King DE, Grossman RG. Alignment correction algorithm for transformation of stereotactic anterior commissure/posterior commissure-based coordinates into frame coordinates for image-guided functional neurosurgery. Neurosurgery 1998;42:806-11.

16 Krauss JK, Grossman RG. Operative techniques for pallidal surgery. In: Krauss JK, Grossman RG, Jankovic J, eds. Pallidal surgery for the treatment of Parkinson's disease and movement disorders. Philadelphia: Lippincott-Raven, 1998:121-33.

17 Krauss JK, Simpson RK, Ondo WG, et al. Concepts and methods in chronic thalamic stimulation for treatment of tremor. Neurosurgery 2001:48:535-43.

18 Krauss JK, Grossman RG. Principles and techniques of movement disorder surgery. In: Krauss JK, Jankovic J, Grossman RG, eds. Surgery for Parkinson's disease and movement disorders. Philadelphia: Lippincot Williams \& Wilkins, 2001:74-109.

19 Koller WC. Sensory symptoms in Parkinson's disease. Neurology 1984;34:957-9.

20 Quinn NP, Koller WC, Lang AE, et al. Painful Parkinson's disease. Lancet 1986;i:1366-9.

21 Goetz CG, Tanner CM, Levy M, et al. Pain in idiopathic Parkinson's disease [abstract]. Neurology 1985;35:200.

22 Schott GD. Pain in Parkinson's disease. Pain 1985;22:407-1 1.

23 Snider SR, Fahn S, Isgreen WP, et al. Primary sensory symptoms in parkinsonism. Neurology 1976;26:423-9.

24 Tandberg E, Larsen JP, Nessler EG. The epidemiology of Parkinson's disease in the county of Rogaland, Norway. Mov Disord 1995; 10:541-9.

25 Quinn N, Critchley P, Marsden CD. Young onset Parkinson's disease. Mov Disord 1987;2:73-91

26 Honey CR, Stoessl AJ, Tsui JKC, et al. Unilateral pallidotomy for reduction of parkinsonian pain. J Neurosurg 1999;91:198-201.
27 Baron MS, Vitek JL, Bakay RAE, et al. Treatment of advanced Parkinson's disease by posterior GPi pallidotomy: 1-year results of a pilot study. Ann Neurol 1996;40:355-66

28 Laitinen LV, Bergenheim AT, Hariz MI. Leksell's posteroventral pallidotomy in the treatment of Parkinson's disease. J Neurosurg 1992;76:53-61.

29 Volkmann J, Sturm V, Weiss P, et al. Bilateral high-frequency stimulation of the internal globus pallidus in advanced Parkinson's disease. Ann Neurol 1998;44:953-61.

30 Limousin P, Krack P, Pollak P, et al. Electrical stimulation of the subthalamic nucleus in advanced Parkinson's disease. N Engl J Med 1998;339:1105-11.

31 Krack $\mathbf{P}$, Pollak $P$, Limousin $P$, et al. From off-period dystonia to peak-dose chorea: the clinical spectrum of varying subthalamic nucleus activity. Brain 1999;122:1133-46.

32 DeLong MR. Primate model of movement disorders of basal ganglia origin. Trends Neurosci 1990;13:281-9.

33 Alexander GE, Crutcher MD. Functional architecture of basal ganglia circuits: neuronal substrates of parallel processing. Trends Neurosci 1990;13:266-71.

34 Wichman T, Delong MR. Functional and pathophysiological models of the basal ganglia. Curr Opin Neurobiol 1996;6:751-8.

35 Krack $\mathbf{P}$, Pollak $P$, Limousin $P$, et al. Opposite motor effects of pallidal stimulation in Parkinson's disease. Ann Neurol 1998;43:180-92.

36 Benazzouz A, Piallet B, Pollak P, et al. Responses of substantia nigra pars reticulata and globus pallidus complex to high frequency stimulation of the subthalamic nucleus in rats: electrophysiological data. Neurosci Lett 1995;189:77-80.

37 Lidsky TI, Manetto C, Schneider JS. A consideration of sensory factors involved in motor functions of the basal ganglia. Brain Res 1985;356:133-46.

38 Menon V, Glover GH, Pfefferbaum A. Differential activation of dorsal basal ganglia during externally and self paced sequences of arm movements. Neuroreport 1998;9:1567-73.

39 Kaji R, Murase N. Sensory function of basal ganglia. Mov Disord 2001;16:507-10.

40 Schneider JS, Diamond SG, Markham CH. Deficits in orofacial sensorimotor function in Parkinson's disease. Ann Neurol 1986; 19:275-82

41 Schneider JS, Diamond SG, Markham CH. Parkinson's disease: sensory and motor problems in arms and hands. Neurology 1987;37:951-6.

42 Klockgether $T$, Borutta $M$, Rapp $H$, et al. A defect of kinesthesia in Parkinson's disease. Mov Disord 1995; 10:460-5.

43 Jobst EE, Melnick ME, Byl NN, et al. Sensory perception in Parkinson disease. Arch Neurol 1997;54:450-4.

44 Demirci M, Grill S, McShane L, et al. A mismatch between kinesthetic and visual perception in Parkinson's disease. Ann Neurol 1997:41:781-8.

45 Sathian K, Zangaladze A, Green J, et al. Tactile spatial acuity and roughness discrimination: impairments due to aging and Parkinson's disease. Neurology 1997;49:168-77.

46 Rickards C, Cody FW. Proprioceptive control of wrist movements in Parkinson's disease. Reduced muscle vibration-induced errors. Brain 1997:120:977-90.

47 Rossini PM, Traversa R, Boccasena P, et al. Parkinson's disease and somatosensory evoked potentials: apomorphine-induced transient potentiation of frontal components. Neurology 1993;43:2495-500.

48 de Mary M, Margari L, Lamberti $P$, et al. Changes in the amplitude of the N30 frontal components of SEPs during apomorphine test in parkinsonian patients. J Neural Trans Suppl 1995;45:171-6.

49 Traversa R, Pierantozzi M, Semprini R, et al. N30 wave amplitude of somatosensory evoked potentials from median nerve in Parkinson's disease: a pharmacological study. J Neural Trans Suppl 1995; 45: 177-85.

50 Nakashima K, Nitta T, Takahashi K. Recovery functions of somatosensory evoked potentials in parkinsonian patients. J Neurol Sci 1992;108:24-31

51 Huttunen J, Teravainen $\mathrm{H}$. Pre- and postcentral cortical somatosensory evoked potentials in hemiparkinsonism. Mov Disord 1993;8:430-6.

52 Drory VE, Inzelberg R, Groozman GB, et al. N30 somatosensory evoked potentials in patients with unilateral Parkinson's disease. Acta Neurol Scand 1998;97:73-6.

53 Boecker H, Ceballos-Baumann A, Bartenstein P, et al. Sensory processing in Parkinson's and Huntington's disease: investigations with 3D $\mathrm{H}_{2}{ }^{15} \mathrm{O}$-PET. Brain 1999;9:1651-65. 